\title{
Immunomodulatory effects of inhaled carbon monoxide on rat syngeneic small bowel graft motility
}

\author{
A Nakao, B A Moore, N Murase, F Liu, B S Zuckerbraun, F H Bach, A M K Choi, \\ M A Nalesnik, L E Otterbein, A J Bauer
}

Gut 2003;52:1278-1285

\begin{abstract}
Background: Intestinal transplantation provokes an intense inflammatory response within the graft muscularis that causes intestinal ileus. We hypothesised that endogenously produced anti-inflammatory substances could be utilised as novel therapeutics. Therefore, we tested the protective effects of inhaled carbon monoxide (CO) and an endogenous haeme oxygenase 1 (HO-1) anti-inflammatory mediator on transplant induced inflammatory responses and intestinal ileus in the rat.

Methods: Gastrointestinal transit of non-absorbable FITC labelled dextran and in vitro jejunal circular muscle contractions were measured in controls and syngeneic orthotopic transplanted animals with and without CO inhalation (250 ppm for 25 hours). Inflammatory mRNAs for interleukin (IL)-6, IL-1 $\beta$, tumour necrosis factor $\alpha$ (TNF- $\alpha)$, intercellular adhesion molecule 1 (ICAM-1), inducible nitric oxide (iNOS), cyclooxygenase 2 (COX-2), and IL-10 were quantified by real time reverse transcriptasepolymerase chain reaction and $\mathrm{HO}-1$ by northern blot. Histochemical stains characterised neutrophil infiltration and enterocyte apoptosis.

Results: Transplantation delayed transit and suppressed jejunal circular muscle contractility. Transplantation induced dysmotility was significantly improved by $\mathrm{CO}$ inhalation. Transplantation initiated a significant upregulation in IL-6, IL- $1 \beta$, TNF- $\alpha$, ICAM- 1 , iNOS, COX-2, and HO- 1 mRNAs with the graft muscularis. CO inhalation significantly decreased expression of IL-6, IL-1 $\beta$, iNOS, and COX-2 mRNAs. CO also significantly decreased serum nitrite levels (iNOS activity).

Conclusions: $\mathrm{CO}$ inhalation significantly improved post-transplant motility and attenuated the inflammatory cytokine milieu in the syngeneic rat transplant model. Thus clinically providing $\mathrm{CO}$, the end product of the anti-inflammatory $\mathrm{HO}-1$ pathway, may prove to be an effective therapeutic adjunct for clinical small bowel transplantation.
\end{abstract}

See end of article for authors' affiliations

S mall intestinal transplantation (SITx) necessitates extrinsic denervation, surgical manipulation, preservation, and ischaemia/reperfusion of the graft, all of which potentially contribute to intestinal dysfunction and paralytic ileus. ${ }^{1-6}$ As early transplantation induced intestinal dysfunction is an important cause of endotoxaemia, the systemic inflammatory response syndrome, and multiorgan failure, these sequelae of transplantation compromise the host and increase the susceptibility of the graft to secondary failure. ${ }^{7-10}$

Haeme oxygenase 1 ( $\mathrm{HO}-1$ ) has been shown to provide protection against oxidative stress via degradation products of haeme. ${ }^{11}{ }^{12}$ The specific mechanism(s) by which HO-1 can mediate these cytoprotective functions are only now beginning to be elucidated but appear to be related to HO- 1 catabolism of haeme, which produces carbon monoxide (CO), iron, and bilirubin. Although $\mathrm{CO}$ is known to be toxic at high concentrations due to its ability to interfere with oxygen delivery, low $\mathrm{CO}$ concentrations provide cytoprotection due to its antiinflammatory, ${ }^{11}$ antigraft rejection, ${ }^{12}$ antiapoptotic, ${ }^{13}$ and cytoprotective properties. ${ }^{14}$ In this study, we examined the ability of exogenous $\mathrm{CO}$ to blunt isograft muscularis inflammation and prevent graft dysmotility.

\section{MATERIALS AND METHODS \\ Experimental groups}

Inbred male LEW (RT. $\left.1^{1}\right)$ rats weighing 200-300 g were purchased from Harlan Sprague Dawley, Inc. (Indianapolis, Indiana, USA) and maintained in a laminar flow animal facility at the University of Pittsburgh under a standard diet and water supplied ad libitum. Specific experimental groups of animals were exposed to $\mathrm{CO}$ at a concentration of $250 \mathrm{ppm}$.
Briefly, $1 \%$ CO in air was mixed with air (21\% oxygen) in a stainless steel mixing cylinder and then directed into a $3.70 \mathrm{ft}^{3}$ glass exposure chamber at a flow rate of $12 \mathrm{l} / \mathrm{min}$. A CO analyser (Interscan, Chatsworth, California, USA) was used to measure CO levels continuously in the chamber. CO concentrations were maintained at $250 \mathrm{ppm}$ at all times. Animals were supplied food and water ad libitum during the exposures.

Four groups of 4-6 animals each were constructed for this study, two of which received a small intestinal transplant: (1) unoperated control rats, (2) unoperated controls exposed to CO for 24 hours, (3) recipients receiving SITx that were exposed to inhaled room air, and (4) recipients receiving a SITx graft which were exposed to CO (250 ppm) for one hour before transplantation and then again for a period of 24 hours following surgery. SITx with caval drainage was performed using a previously described procedure. ${ }^{15}$

\section{Functional studies}

The effect of CO treatment on intestinal motility in controls and transplanted grafts was assessed both in vivo and in vitro

Abbreviations: $\mathrm{BSA}$, bovine serum albumin; $\mathrm{CO}$, carbon monoxide; SITx, small intestinal transplantation; GAPDH, glyceraldehyde-3-phosphate dehydrogenase; HO- 1, haeme oxygenase 1; COX-2, cyclooxygenase 2 ; iNOS, inducible nitric oxide; NO, nitric oxide; ICAM-1, intercellular adhesion molecule 1; IL, interleukin; TNF- $\alpha$, tumour necrosis factor $\alpha$; MPO, myeloperoxidase; PBS, phosphate buffered saline; PMNs, polymorphonuclear neutrophils; RPA, RNase protection assay; RT-PCR, reverse transcriptase-polymerase chain reaction; SDS, sodium dodecyl sulphate. 


\begin{tabular}{|c|c|c|}
\hline Primer & Sequence $5^{\prime}$ to $3^{\prime}$ & Source \\
\hline GAPDH & $\begin{array}{l}\text { ATGGCACAGTCAAGGCTGAGA } \\
\text { CGCTCCTGGAAGATGGTGAT }\end{array}$ & NM_017008 \\
\hline IL-6 & $\begin{array}{l}\text { GCCCTTCAGGAACAGCTATGA } \\
\text { TGTCAACAACATCAGTCCCAAGA }\end{array}$ & M26744 \\
\hline IL-1 $\beta$ & $\begin{array}{l}\text { CACCTCTAAGCAGAGCACAG } \\
\text { GGGTTCCATGGTGAAGTCAAC }\end{array}$ & $\begin{array}{l}\text { Li and Wang (Brain Res Brain Res Protoc } \\
2000 ; 5: 211-17 \text { ). }\end{array}$ \\
\hline TNF- $\alpha$ & $\begin{array}{l}\text { GGTGATCGGTCCCAACAAGGA } \\
\text { CACGCTGGCTCAGCCACTC }\end{array}$ & Fink, et al (Nat Med 1998;4:1329-33). \\
\hline ICAM-1 & $\begin{array}{l}\text { CGTGGCGTCCATTTACACCT } \\
\text { TTAGGGCCTCCTCCTGAGC }\end{array}$ & NM_012967 \\
\hline iNOS & $\begin{array}{l}\text { GGAGAGATTTTCACGACACCC } \\
\text { CCATGCATAATTTGGACTTGCA }\end{array}$ & NM_012611 \\
\hline $\operatorname{cox}-2$ & $\begin{array}{l}\text { CTCTGCGATGCTCTTCCGAG } \\
\text { AAGGATTTGCTGCATGGCTG }\end{array}$ & AF233596 \\
\hline IL-10 & $\begin{array}{l}\text { TGCAACAGCTCAGCGCA } \\
\text { GTCACAGCTTTCGAGAGACTGGAA }\end{array}$ & Harness, et al (J Neurol Sci $2001 ; 187: 7-16)$ \\
\hline
\end{tabular}

( $n=4-6$ each $)$. Intestinal transit was measured in controls and transplanted animals 48 hours postoperatively by evaluating the gastrointestinal distribution of orally fed fluorescein labelled dextran (Molecular Probes, Eugene, Oregon, USA), and intestinal transit was statistically analysed using the calculated geometric centre, as previously described. ${ }^{16}$

Intestinal tissues were harvested 24 hours postoperatively, the time point at which transplant induced in vitro dysmotility peaks. ${ }^{6}$ Circular muscle mechanical activity was measured and analysed as previously described. ${ }^{17}$

\section{Morphological studies}

Histopathological

Small intestinal grafts at four hours and 24 hours were fixed in $10 \%$ buffered formalin and embedded in paraffin $(n=4$ each). Sections were cut at a thickness of $4 \mu \mathrm{m}$ and stained with haematoxylin and eosin. Mucosal apoptotic cells with routine histopathology characteristics were counted in haematoxylin and eosin cross sections. Slides were blindly reviewed by one of the authors (MAN), a pathologist, without knowledge of the experimental groups.

\section{Myeloperoxidase histochemistry}

Muscularis whole mounts were prepared from the mid small intestine collected 24 hours postoperatively and Hanker-Yates reagent was used for detection and quantification of polymorphonuclear neutrophils (PMNs) exhibiting myeloperoxidase (MPO) activity. ${ }^{18}$

\section{Molecular biological studies}

\section{RNase protection assay (RPA)}

To investigate the sequential analysis of cytokine mRNA expression in the graft, RNase protection assays (RPAs) were performed with the Riboquant kit (Pharmingen) according to the manufacturer's protocol. A jejunal segment of the graft was dissected and immediately snap frozen in liquid nitrogen for RPA. Total RNA extraction was performed on each isolated gut layer using the guanidium-thiocyanate phenolchloroform extraction method, as described previously. ${ }^{19}$ Radiolabelled antisense RNA multiple probes were synthesised using an in vitro transcription kit and rat cytokine multi-probe template set (rCK-1), which included probes for cytokines (interleukin (IL)-1 $\beta$, IL-1 $\alpha$, IL-2, IL-3, IL-4, IL-5, IL-6, IL-10, tumour necrosis factor $\alpha$ (TNF- $\alpha$ ), TNF- $\beta$, and interferon $\gamma$ ) and housekeeping genes (L32 and glyceraldehyde-3-phosphate dehydrogenase (GAPDH)). ${ }^{32} \mathrm{P}$ labelled probes $\left(8.0 \times 10^{5} \mathrm{cpm}\right)$ and sample RNA $(5 \mu \mathrm{g})$ were hybridised at $56^{\circ} \mathrm{C}$ for $12-16$ hours and single stranded RNAs, including antisense RNA probes, were digested using RPA Kit
(Pharmingen, San Diego, California, USA). Protected probes were loaded onto a $40 \%$ polyacrylamide gel electrophoresis and autoradiography was performed using a PhosphorImager system (Molecular Dynamics, Krefeld, Germany). Quantification of radioactivity of mRNA bands was done with NIH Image, normalised to GAPDH, and expressed as a ratio of cytokine/GAPDH $(\mathrm{n}=3-4)$.

\section{SYBR green real time RT-PCR}

The effects of $\mathrm{CO}$ inhalation on transplant induced proinflammatory and anti- inflammatory gene expression was assessed in muscularis extracts by reverse transcriptase- polymerase chain reaction ( $\mathrm{RT}-\mathrm{PCR}$ ) ( $\mathrm{n}=4-6$ each group). Muscularis externa was collected from control intestine and transplanted grafts four hours following reperfusion, and snap frozen in liquid nitrogen. This time point falls within the range of maximum inflammatory mediator expression that occurs between three and six hours following reperfusion, based on RPA results. The extracted RNA pellets were resuspended in RNA secure resuspension solution (Ambion Inc., Austin, Texas, USA) followed by removal of potential contaminating DNA by treatment with DNase I (DNA-Free Kit, Ambion Inc.). Equal aliquots $(5 \mu \mathrm{g})$ of total RNA from each sample were quantified by spectrophotometry (wavelength $250 \mathrm{~nm}$ ) and aliquoted at a concentration of $40 \mathrm{ng} / \mu \mathrm{l}$. Primers were taken from the literature or designed according to published sequences (table 1). Peak mRNA expression was quantified in duplicate by SYBR green two step real time RT-PCR and quantification of mRNA expression was normalised to GAPDH and calculated relative to control using the comparative CT method. ${ }^{19} 20$

\section{HO- 1 analysis}

Northern blot analysis was performed as previously described Briefly, $10 \mu \mathrm{g}$ of total RNA extracted from the tissue, as described above, was electrophoresed on a $1 \%$ agarose gel and transferred to nylon membranes by capillary action. Nylon membranes were then prehybridised in buffer $(1 \%$ bovine serum albumin (BSA), 7\% sodium dodecyl sulphate (SDS), $0.5 \mathrm{M}$ PO4 buffer, $\mathrm{pH} 7.0$, and $1 \mathrm{mM}$ EDTA) at $65^{\circ} \mathrm{C}$ for two hours followed by hybridisation with ${ }^{32} \mathrm{P}$ labelled rat $\mathrm{HO}-1$ cDNA at $65^{\circ} \mathrm{C}$ for 24 hours. Nylon membranes were then washed in buffer A $(0.5 \%$ BSA, 5\% SDS, $40 \mathrm{mM}$ PO4 buffer, $\mathrm{pH}$ 7.0, and $1 \mathrm{mM}$ EDTA) for 15 minutes, twice, at $65^{\circ} \mathrm{C}$ followed by washes in buffer B ( $1 \%$ SDS, 40 mM PO4 buffer, pH 7.0, and $1 \mathrm{mM}$ EDTA) for 15 minutes, three times, at $65^{\circ} \mathrm{C}$.

\section{HO- 1 cDNA probe}

A full length rat cDNA ( $\mathrm{pHOl}$ ) was generously provided by Dr S Shibahara of Tohoku University (Sendai, Japan). pHOl was 


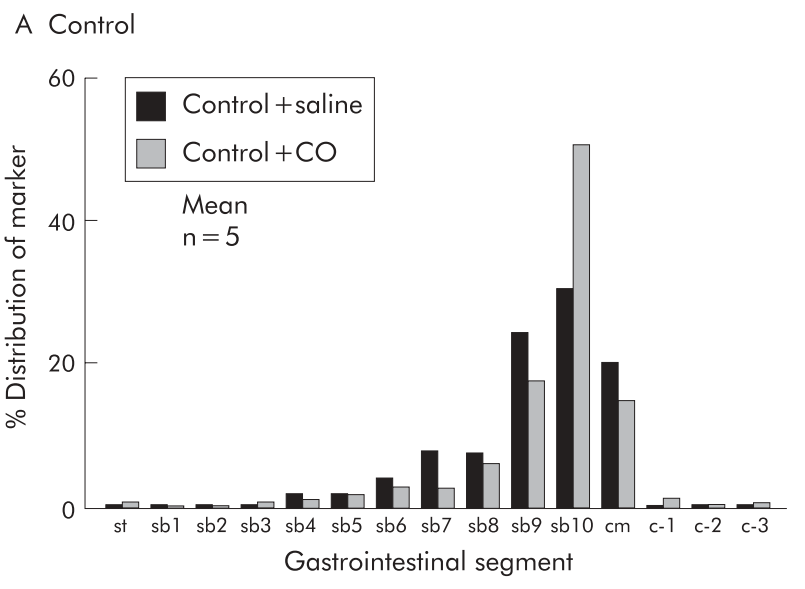

B Small intestinal transplant

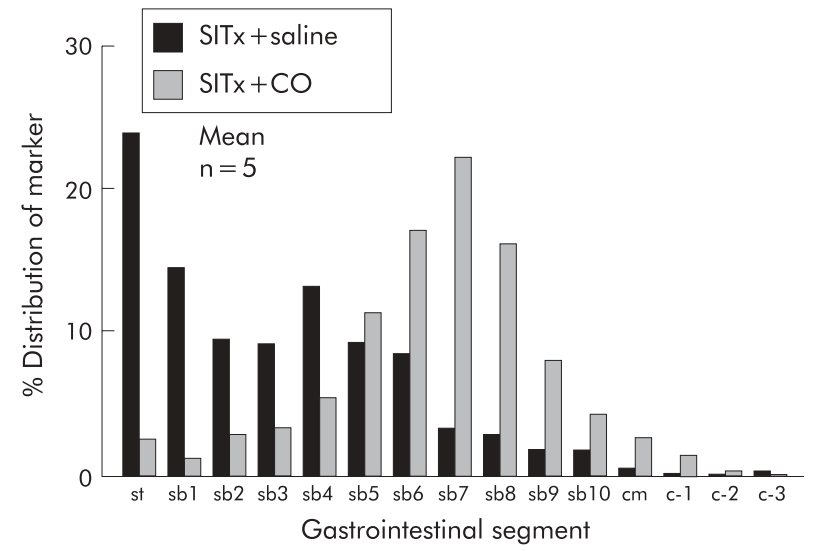

C Transit geometric centres

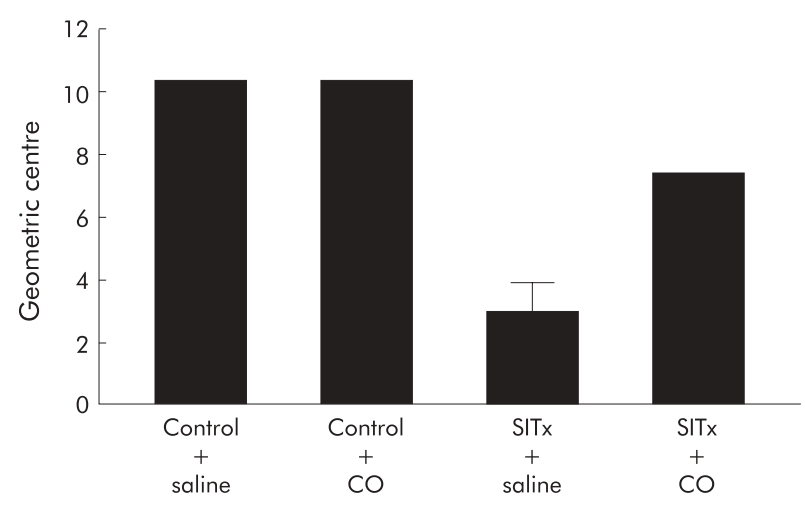

Figure 1 Transit histograms for distribution of non-absorbable FITC labelled dextran along the gastrointestinal tract two hours after oral administration. In unoperated animals and control animals exposed to carbon monoxide (CO), most of the fluorescent marker accumulated in the last two segments of the small bowel (sb) and caecum (c) (A). In contrast, small intestinal transplantation (SITX) caused significant delay in the transit of the fluorescence (B). In transplanted $\mathrm{CO}$ treated animals $(\mathrm{B})$, most of the fluorescent marker accumulated in distal segments of the small bowel (sb6, 7, and 8), which was similar to unoperated animals. The calculated transit geometric centre measurements summarised in (C) demonstrated that $\mathrm{CO}$ inhalation significantly improved gastrointestinal transit after SITx. Data represent averaged per cent distribution of fluorescence intensity from four animals (st, stomach). ${ }^{*} p<0.05$.

subcloned into pBluescript vector, and a HindIII/EcoRI digestion was performed to isolate the $0.9 \mathrm{~kb}$ HO- $\mathrm{l}$ cDNA insert out of the pBluescript vector. To control for variation in either the amount of RNA in different samples or loading errors, blots
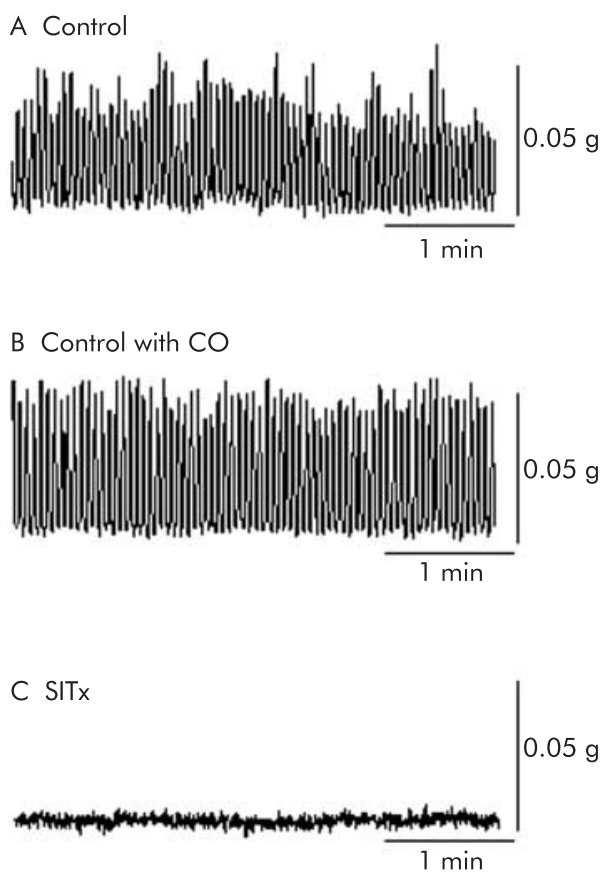

D SITx with CO

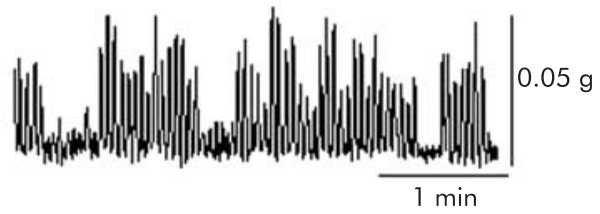

Figure 2 Representative traces of spontaneous jejunal circular muscle contractility are shown. Circular muscle strips from unoperated control intestine and carbon monoxide $(\mathrm{CO})$ treated control intestine exhibited robust spontaneous activity (A, B). Small intestinal transplantation (SITx) resulted in a significant decrease in spontaneous circular muscle contraction (C). However, CO treatment demonstrated significantly greater spontaneous contractile activity compared with untreated transplants.

were hybridised with an oligonucleotide probe corresponding to the 18S rRNA. A 24 base pair oligonucleotide (5'ACGGTATCTGATCGTCTTCGAACC-3') complementary to the 18S RNA was synthesised using a DNA synthesiser (Applied Biosystems, Foster City, California, USA). HO-l cDNA was labelled with $\left[{ }^{32} \mathrm{P}\right]$ CTP using the random primer kit from Boehringer Mannheim (Mannheim, Germany). All oligonucleotide probes were labelled with $\left[{ }^{32} \mathrm{P}\right]$ ATP at the $3^{\prime}$ end with terminal deoxynucleotidyltransferase (Bethesda Research Laboratories, Gaithersburg, Maryland, USA). Autoradiograph signals were compared with 18S rRNA obtained from the same blot.

\section{Detection of serum mediators}

Serum samples were taken at four hours after reperfusion and stored at $-80^{\circ} \mathrm{C}$ until evaluation ( $\mathrm{n}=4$ from each group). Serum cytokine concentrations, including IL-6 and IL-10, were determined using rat enzyme linked immunoassay kits, as described by the manufacturer (R\&D, Cambridge, Massachusetts, USA). Nitric oxide (NO) secretion (serum nitrite/nitrate) was measured four hours after engraftment using a commercially available test kit (Cayman, Ann Arbor, Michigan, USA).

\section{Data analysis}

Results are expressed as mean (SEM). Statistical analysis was performed using the Student's $t$ test or analysis of various (ANOVA) where appropriate. Statistical analysis for multiple 


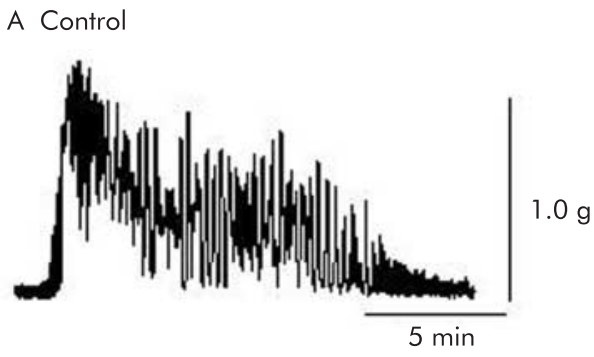

B Control with $\mathrm{CO}$

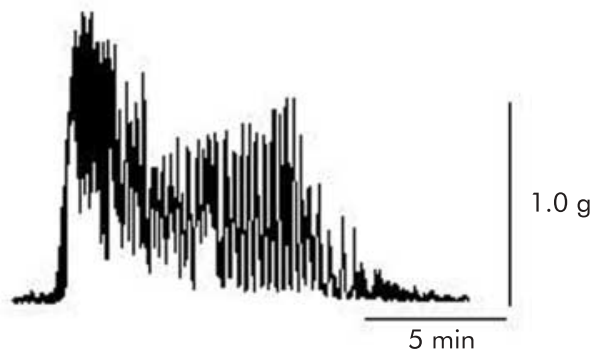

C SITx
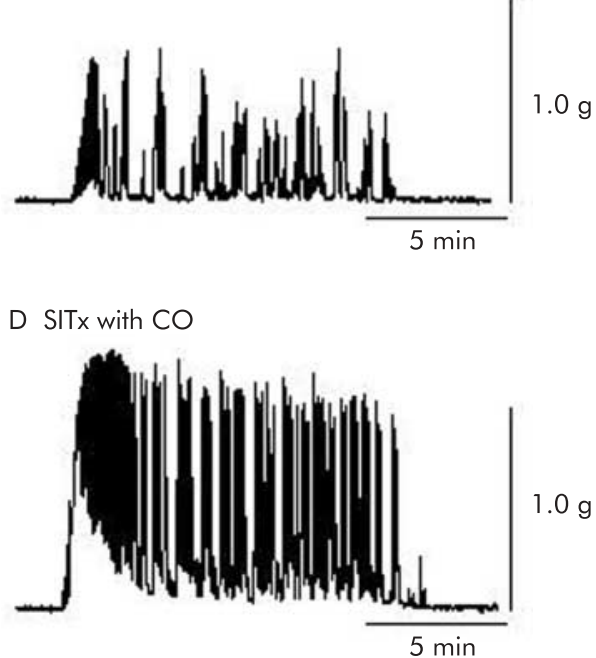

Figure 3 Representative in vitro jejunal circular smooth muscle contractile activity recorded in response to bethanechol (100 $\mu \mathrm{M})$ from the four groups of animals. Unoperated circular smooth muscles showed large phasic and tonic responses to bethanechol at higher concentrations (A, B). The response to bethanechol was significantly suppressed in circular smooth muscles harvested from untreated transplanted animals (C). Carbon monoxide (CO) inhalation of transplanted animals demonstrated a significant improvement in bethanechol stimulated contractions (D). SITx, small intestinal transplantation.

comparisons used the Student-Neuman-Keul's test. A probability level of $\mathrm{p}<0.05$ was considered statistically significant.

\section{RESULTS}

\section{Functional studies}

The effects of SITx and CO inhalation on intestinal function was investigated by measuring the intestinal distribution of orally fed fluorescein labelled dextran (that is, gastrointestinal transit for a period of two hours) in controls and transplanted animals 48 hours postoperatively. The average gastrointestinal transit distribution histograms of the fluorescence signal contained in each bowel segment from the stomach to the colon are plotted in fig $\mathrm{IA}$ and $\mathrm{IB}$ for unoperated controls, controls receiving CO inhalation, SITx animals, and SITx animals receiving $\mathrm{CO}$ inhalation. As shown in fig $1 \mathrm{~A}, \mathrm{CO}$ inhalation did

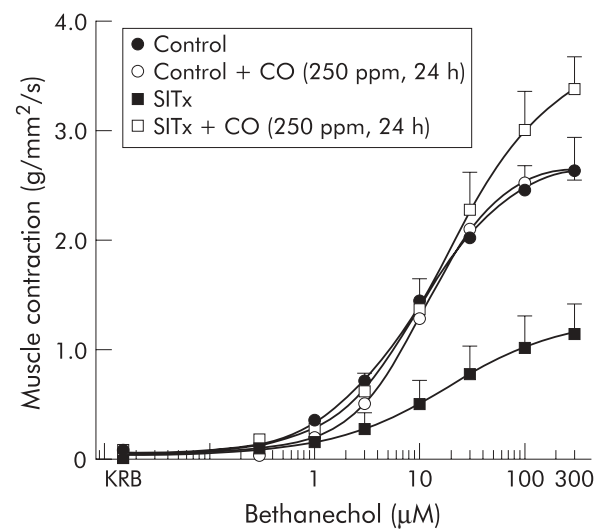

Figure 4 Jejunal circular muscle strips from control animals and unoperated animals receiving carbon monoxide (CO) inhalation showed a dose dependent increase in contractile area in response to bethanechol. This activity was significantly diminished in graft circular muscle strips taken 24 hours following small intestinal transplantation (SITx). Significant improvement was measured in transplanted animals treated with $\mathrm{CO}(\mathrm{n}=4$ each).

not alter gastrointestinal transit distribution histograms measured from control animals, with the majority of the fluorescent label being localised to the end of the small intestine and caecum. Statistical analyses of the geometric centre calculations were similar between the two groups (see fig lC).

Intestinal transplantation caused a significant delay in gastrointestinal transit (fig lB). ${ }^{6}$ The intestinal anastomosis sites in segments 3 and 11 did not appear to influence transit. In sharp contrast, recipient transplanted animals treated with CO displayed a markedly increased more normal gastrointestinal transit with the fluorescein labelled dextran progressing down to the distal segments of the small intestine. The calculated transit geometric centre measurements summarised in fig $1 \mathrm{C}$ demonstrate that CO inhalation therapy significantly increased gastrointestinal transit in rats undergoing SITx.

Secondly, the effects of SITx with and without CO inhalation treatment were investigated on spontaneous and bethanechol stimulated jejunal circular muscle contractility using in vitro organ bath experiments. Tissues were harvested 24 hours after transplantation of the intestinal graft, a time point when intestinal motility associated with SITx is known to be maximally suppressed. ${ }^{6}$ Representative traces of spontaneous jejunal circular muscle contractility are shown in fig 2 . Circular muscle strips from unoperated control intestine generated regular contractions with a mean contractile area of $0.96(0.16) \mathrm{g} / \mathrm{mm}^{2} / \mathrm{s}$ (fig 2A). Control animals that breathed $\mathrm{CO}$ in the inhalation chambers for 24 hours demonstrated no change in their spontaneous circular muscle contractile activity $\left(1.02(0.15) \mathrm{g} / \mathrm{mm}^{2} / \mathrm{s}\right)$ (fig $\left.2 \mathrm{~B}\right)$. As we have previously demonstrated, SITx results in a significant decrease in spontaneous circular muscle contractile activity (fig $2 \mathrm{C}$ ). Interestingly, jejunal circular muscle strips harvested from the graft, which had been transplanted into the recipient animals that received $\mathrm{CO}$ for 24 hours, demonstrated significantly greater spontaneous contractile activity compared with untreated transplants $\left(0.73(0.10) \mathrm{g} / \mathrm{mm}^{2} / \mathrm{s}\right)$ (fig 2D).

Addition of bethanechol $(0.3-300 \mu \mathrm{M})$ to the bathing superfusate elicited a concentration dependent increase in circular muscle contractility. Representative $100 \mu \mathrm{M}$ bethanechol stimulated contractility traces recorded from jejunal circular muscle strips for the four groups of animals are shown in fig 3. Control circular muscles from untreated (3.5 (0.7) $\left.\mathrm{g} / \mathrm{mm}^{2} / \mathrm{s}\right)$ and CO treated $\left(3.2(0.5) \mathrm{g} / \mathrm{mm}^{2} / \mathrm{s}\right)$ animals exhibited similar robust phasic and tonic contractions to bethanechol $(100 \mu \mathrm{M})$, while circular muscles from the untreated transplanted intestine generated significantly less 
Table 2 Microscopic visual examination of mucosal crypts ( $n=10$ each) for apoptotic enterocytes. $\mathrm{CO}$ inhalation did not significantly change enterocyte apoptosis caused by small intestinal transplantation

\begin{tabular}{llllc}
\hline & Erosion & Villous congestion & Re-epithelialisation & Apoptosis/10 crypts \\
\hline Control & 0 & 0 & 0 & $3.0(2.3)$ \\
Control+CO & 0 & 0 & 0 & $1.3(0.5)$ \\
SITx & $0.8(1.5)$ & $0.5(1.0)$ & $0.5(1.0)$ & $8.8(6.1)$ \\
SIT $x+\mathrm{CO}$ & 0 & $0.3(0.6)$ & $0.7(1.2)$ & $12.3(12.9)$ \\
\hline
\end{tabular}

$\mathrm{CO}$, carbon monoxide; SITx, small intestinal transplantation.

contractility $(51 \%)$ in response to bethanechol (1.7 (0.4) $\mathrm{g} / \mathrm{mm}^{2} / \mathrm{s}$ ). However, bethanechol stimulated circular muscle

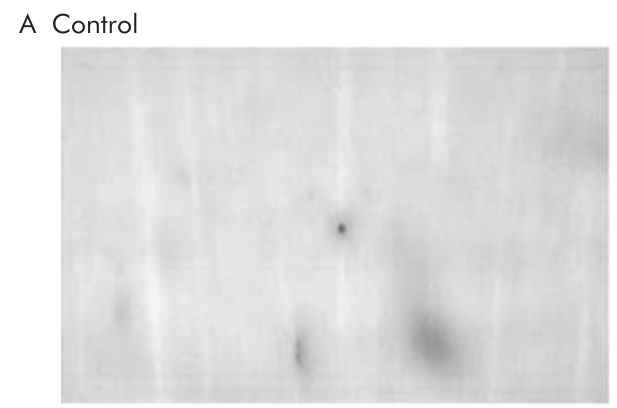

B SITx
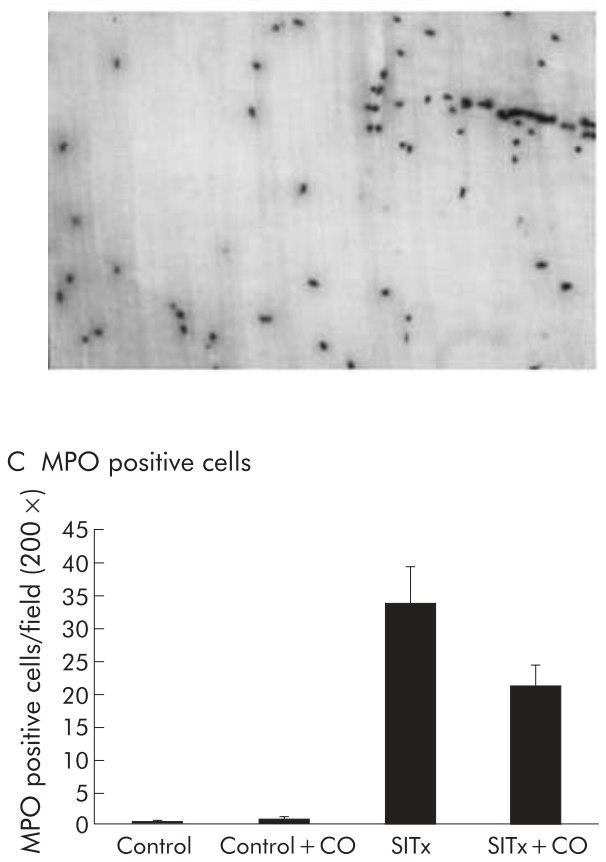

Figure 5 Typical histochemically stained full thickness muscularis whole mounts for the presence of myeloperoxidase positive (MPO) polymorphonuclear neutrophils (PMNs) extravasated into muscularis. (A) Typical muscularis whole mount from an unoperated control animal which was virtually devoid of MPO positive leucocytes. (B) Presence of numerous extravasated PMNs within the graft muscularis taken from the animal 24 hours after small intestinal transplantation (SITX). (C) Histogram quantifying the number of extravasated neutrophils within full thickness whole mounts of jejunal muscularis externa from the four groups of animals ( $n=4$ each). As reflected in the histological analysis, SITx resulted in a significant cellular inflammatory response within the muscularis. Carbon monoxide (CO) inhalation decreased the number of MPO positive cells which extravasated into muscularis in response to transplantation. contractility generated by $\mathrm{CO}$ treated animals was significantly improved over the untreated graft circular muscles (3.6 $(0.7) \mathrm{g} / \mathrm{mm}^{2} / \mathrm{s}$ ). These observations were reflected throughout the generation of the complete integrated contractile bethanechol dose-response curves for each of the four groups of animals.

As shown in fig 4, CO inhalation therapy completely prevented the transplant induced suppression in circular muscle contractility, restoring the response of circular muscle to pretransplant levels.

\section{Enterocyte histopathology}

In unoperated controls and control CO treated rats, apoptotic cells were rarely found in crypts ( $<5$ apoptotic cells/10 crypts) Intestinal transplantation significantly increased apoptosis in crypts and villous lamina propria after four hours of graft reperfusion. Microscopic examination of the effects of $\mathrm{CO}$ inhalation did not show any significant change in enterocyte apoptosis (table 2).

\section{Leucocyte recruitment}

Cellular inflammatory events in the small intestinal muscularis were characterised 24 hours after SITx. MPO activity, as determined by Hanker-Yates histochemistry, was used to quantify the PMN infiltrate in tissues from control and transplanted animals, with and without CO treatment. Photomicrographs of muscularis whole mounts showing MPO positive

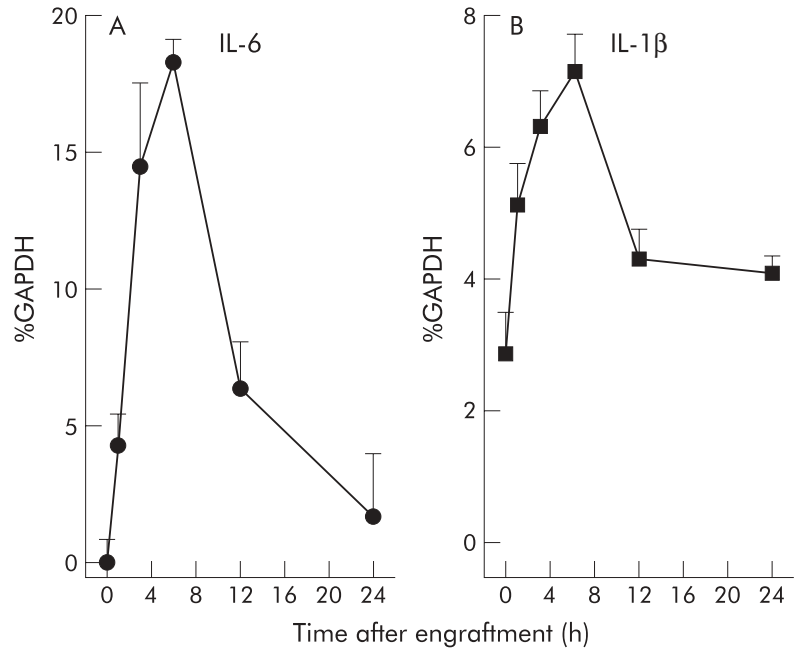

Figure 6 Sequential analysis of cytokine mRNA measured by RNase protection assay demonstrated that small intestinal transplantation (SITX) resulted in significant upregulation of both interleukin (IL)- 6 and IL-1 $\beta$ mRNAs, which peaked between three and six hours within the graft wall. Data points in (A) at $1,3,6$, and 12 hours and data points in (B) at 1,3 , and 6 were significantly different $(p<0.05)$ over control extracts by multiple comparisons (Student-Neuman-Keul's test). Values are mean (SEM), $n=4$ each. GAPDH, glyceraldehyde- 3-phosphate dehydrogenase. 

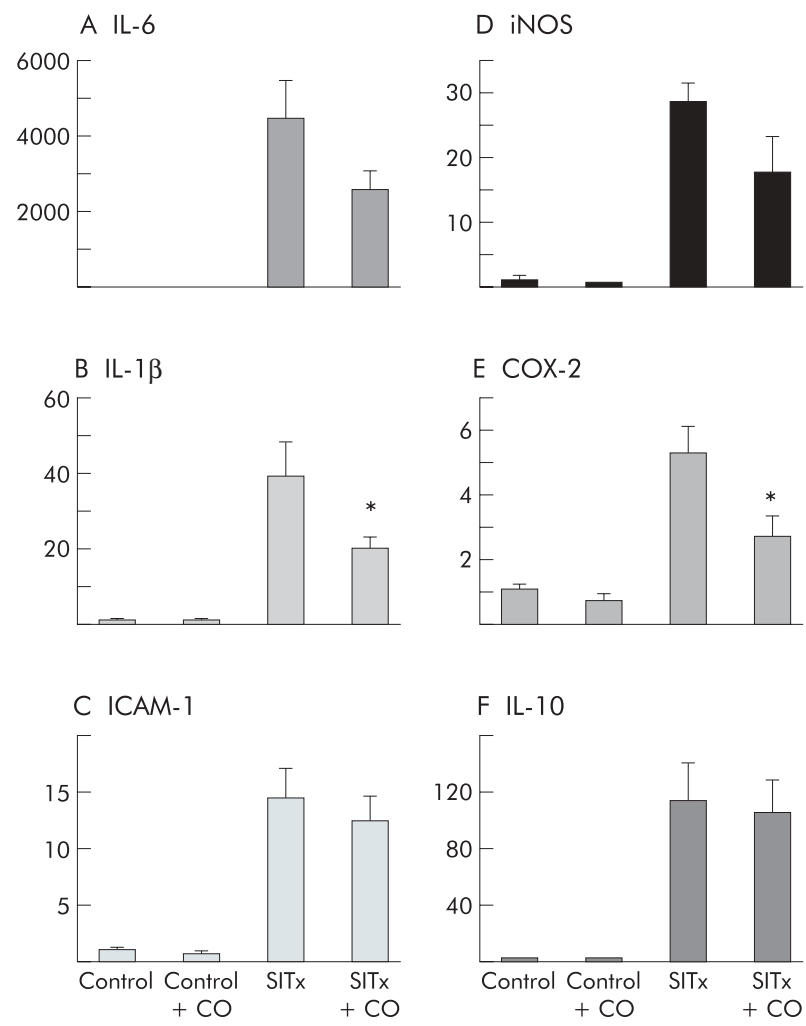

Figure 7 Real time reverse transcriptase-polymerase chain reaction analysis revealed a significant increase in mRNA expression of interleukin (IL)-6, IL-1 $\beta$, and intercellular adhesion molecule 1 (ICAM-1) in graft muscularis four hours after small intestinal transplantation (SITX) compared with unoperated animals $(A, B, C)$. In recipients treated with carbon monoxide $(\mathrm{CO})$, mean expression of IL- 6 and IL- $1 \beta$ mRNA, but not ICAM- 1 , were significantly reduced by greater than $40 \%$. Inducible nitric oxide (iNOS) and cyclooxygenase 2 (COX-2) gene expression were also significantly upregulated in the muscularis of the transplanted intestine $(D, E) . C O$ exposure tended to reduced expression of iNOS $(p<0.08)$ and significantly decreased COX-2 mRNA in the graft muscularis extracts. IL-10 expression was upregulated over 100-fold by SITx but $\mathrm{CO}$ inhalation did not affect IL- 10 expression four hours after reperfusion $(F)\left({ }^{*} p<0.05\right)$.

cells infiltrating the muscle layers are shown in fig 5. In unoperated control and CO treated control rats, MPO positive cells were rare (fig 5A). SITx resulted in a significant recruitment of PMNs into the intestinal muscularis (fig 5B). Cell counts per $200 \times$ field are summarised in fig 5C, which demonstrates that $\mathrm{CO}$ treatment decreased the mean number of MPO positive cells; however, this reduction did not achieve statistical significance $(\mathrm{p}=0.08, \mathrm{n}=6)$.

\section{Molecular inflammatory responses}

RPAs demonstrated that SITx caused significant upregulation of both IL- 6 and IL-1 $\beta$ mRNAs, which peaked 3-6 hours within the transplanted graft (fig 6). Based on these findings, we chose four hours following reperfusion as a time point for quantitative analysis of mRNA levels of various prototypical inflammatory mediators.

Real time RT-PCR analysis revealed a significant increase in mRNA expression for the proinflammatory cytokines IL-6 and IL-1 $\beta$ in graft muscularis externa extracts four hours after reperfusion compared with unoperated controls (fig 7A, 7B). Intercellular adhesion molecule 1 (ICAM-1) gene expression, an adhesion molecule that plays an important role in the recruitment of circulating inflammatory cells into inflamed tissues, was also significantly increased 14.6 (2.55)-fold com-
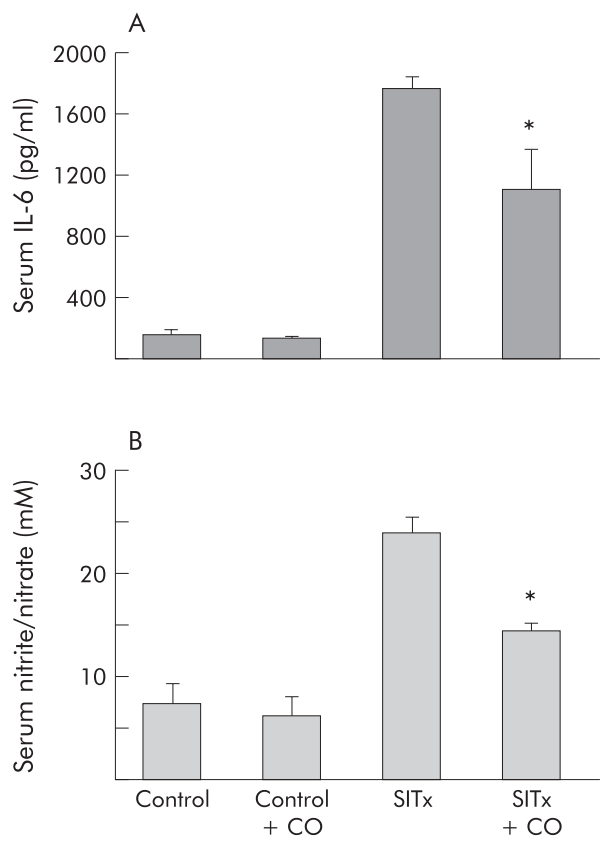

Figure 8 Serum interleukin 6 (IL-6) levels in the small intestinal transplantation (SITx) group were significantly higher than those in unoperated animals. Carbon monoxide (CO) inhalation significantly reduced serum IL- 6 levels in transplanted animals (A). SITx resulted in elevation of serum nitric oxide products four hours after reperfusion. $\mathrm{CO}$ treated transplanted animals showed significantly lower levels than animals exposed to room air (B). ${ }^{*} p<0.05$.

pared with controls (fig 7C). But at the four hour time point studied, TNF- $\alpha$ was not significantly upregulated (2.9 (1.94)fold).

In graft muscularis extracts of recipient rats treated with CO, mean comparative expression of IL-6 and IL-1 $\beta$ was reduced on average by $40 \% \quad(p=0.084, n=6)$ and $50 \%$ $(p=0.046, n=6)$, respectively, compared with the untreated transplanted and reperfused graft at four hours (fig 7A, 7B). The decreased expression of IL-6 mRNA was also reflected in protein production. As shown in fig $8 \mathrm{~A}$, in untreated and CO treated controls, serum IL-6 concentrations were low. Transplantation caused a significant increase in serum IL-6 protein concentrations (1758 (77.8) pg/ml) four hours after engraftment and the serum IL-6 increase was significantly less in recipients that had received CO inhalation therapy (1096 (260) pg/ml). However, unlike IL-6 and IL-1 $\beta$, CO inhalation did not significantly change the upregulation of TNF- $\alpha$ or ICAM-1 caused by transplantation (2.8 (0.44)-fold and 12.5 (2.29)-fold, respectively). CO inhalation by control animals also did not alter basal mRNA expression of any of the cytokines.

$\mathrm{NO}$ and prostanoids play a significant role in causing intestinal dysmotility in other models of intestinal inflammation. ${ }^{172122}$ Therefore, gene expression of inducible nitric oxide synthase (iNOS) and cyclooxygenase (COX-2) were quantified by real time RT-PCR. The results showed that both iNOS and COX-2 were significantly upregulated 28.4-fold and fivefold, respectively, in the graft muscularis (fig 7D, 7E). Mean relative mRNA expression of both enzymes was reduced by approximately $50 \%$ in $\mathrm{CO}$ treated rats $(\mathrm{p}=0.060$ and $\mathrm{p}=0.26, \mathrm{n}=6$ each). CO inhalation by unoperated control animals did not alter mRNA expression of iNOS or COX-2. We followed the molecular expression of iNOS with measurement of nitric oxide metabolites in the serum of transplanted animals. In air and $\mathrm{CO}$ treated controls, mean serum nitrite/nitrate (NO) levels determined by the Griess reaction were $7.2(2.1)$ and 6.1 (1.9) $\mu \mathrm{M}$. As predicted by the molecular upregulation of iNOS mRNA, SITx resulted in a significant 


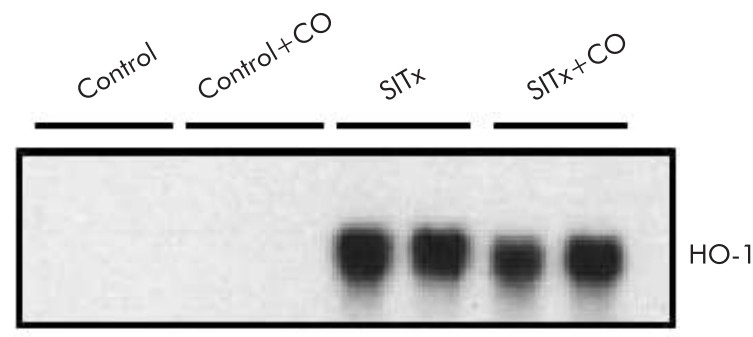

18 s rRNA

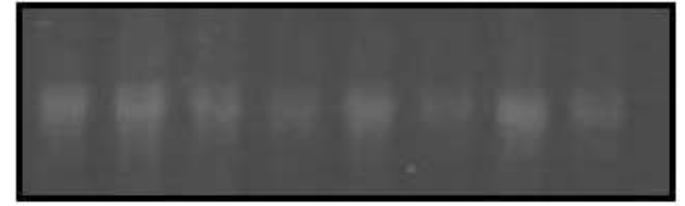

Figure 9 Northern blot for haeme oxygenase 1 (HO-1) demonstrated that $\mathrm{HO}-1$ mRNA upregulation was found in the small intestinal transplantation (SITX) intestinal muscularis four hours after transplantation. Carbon monoxide (CO) treatment did not affect expression of $\mathrm{HO}-1$ at this particular time point. The bands of $\mathrm{HO}-1$ were not visible in both unoperated control and $\mathrm{CO}$ treated intestinal muscularis. Ethidium bromide staining is shown to verify equal loading.

elevation of serum NO products to 23.7 (1.1) $\mu \mathrm{M}$ four hours after engraftment. Likewise, in concert with the mRNA data, CO treatment significantly decreased transplant induced serum nitrite levels by $40 \%$ to 14.2 (2.5) $\mu \mathrm{M}$ (fig $8 \mathrm{~B}$ ).

We next sought to determine if the blunted proinflammatory responses could be mechanistically mediated through an increase in the IL-10 and HO- 1 anti-inflammatory pathways. Our data demonstrated that transplantation caused a significant 118-fold increase in muscularis IL-10 mRNA expression four hours after engraftment. However, CO treatment of transplants did not affect the increased IL-10 expression four hours after reperfusion (fig 7F). Serum IL-10 concentrations mimicked these muscularis mRNA determinations with an increase in serum IL-10 following transplantation. CO did not alter this serum increase in IL-10 protein at four hours (data not shown).

The HO- 1 gene has not been sequenced in the rat for RT-PCR experiments but northern blot analyses clearly showed a transplant induced increase in HO-1 in muscle extracts. HO- 1 mRNA expression was not detected by northern blot in the intestinal muscularis of unoperated animals. However, dense bands of HO-l were visible four hours after SITx in animals with and without $\mathrm{CO}$ inhalation $(\mathrm{n}=4$ each), but this induction was equally intense by densitometry in both transplanted groups (fig 9).

\section{DISCUSSION}

The unique immunological characteristics of the gastrointestinal tract have made the realisation of successful clinical small bowel transplantation a Sisyphean task. Unfortunately, the proinflammatory and anti-inflammatory events within the specific structures of the gut wall that are initiated by transplantation and rejection of the bowel are poorly understood. We and others have observed that proinflammatory molecular and cellular events play a vital role in damaging the bowel following syngeneic transplantation, ${ }^{53}$ acute rejection, ${ }^{24} 25$ and chronic rejection. ${ }^{26-28}$ However, the potential of specific anti-inflammatory molecular events, which could be therapeutically exploited to limit inflammation and avert functional changes of the intestinal graft, are completely unexplored. We hypothesised that pharmacologically providing the end products of anti-inflammatory pathways will significantly prevent the development of detrimental molecular and functional alterations within the intestinal graft following transplantation.
The inducible isoform of haeme oxygenase, HO- 1 , is a ubiquitous heat shock protein (HSP32) that is highly induced by diverse stress related conditions. ${ }^{11}{ }^{12}{ }^{29-38}$ We hypothesised that CO inhalation therapy could play a seminal therapeutic role in the success of SITx, as it was shown to prevent rejection in a heart model of mouse to rat xenotransplantation, ${ }^{12}$ as well as ischaemia/reperfusion injury in the lung. ${ }^{39}$

Post-transplant gastrointestinal motility is markedly suppressed due to a variety of injurious stimuli, including harvest, preservation, manipulation, and sepsis, as well as rejection. ${ }^{5619}$ We have previously shown that syngeneic SITx, as well as the isolated events of intestinal manipulation and sepsis, result in a significant delay in intestinal transit, a decrease in circular muscle strip contractility, and massive neutrophilic infiltration into the muscularis. ${ }^{6041}$ The data presented above demonstrate a similar finding of suppressed gastrointestinal transit, decreased in vitro circular muscle contractility, and leucocyte recruitment into the transplanted intestinal muscularis. As hypothesised, CO inhalation therapy significantly prevented the transplant induced delay in gastrointestinal transit and suppression in jejunal circular muscle contractility in vitro. Interestingly, the improvement in motility occurred in the absence of a significant decrease in PMN infiltration which appeared to be mechanistically confirmed based on the fact that post-transplant ICAM-1 mRNA levels were not altered by $\mathrm{CO}$ inhalation. It would appear that in this model, $\mathrm{CO}$ is primarily modulating leucocyte function to improve motility.

The data above reconfirmed that intestinal transplantation induces a complex molecular and cellular inflammatory response within the graft muscularis. Our results showed that CO significantly decreased the transplant induced upregulation of the inflammatory cytokines IL- 6 and IL- $1 \beta$. These two cytokines have important immune/inflammatory functions but their downregulation may also have a significant impact directly on motility because of their ability to modulate neuromuscular transmission. ${ }^{42-44}$

Muscularis macrophages play a key autocrine role in regulating smooth muscle contractility through their proclivity to produce NO and prostanoids. ${ }^{19}$ Here we showed significant upregulation of iNOS and COX-2 within the graft muscularis. A likely mechanism for improved motility in CO treated animals is the finding that the mean relative mRNA expression of both enzymes was reduced by approximately $50 \%$ in CO treated rats. Also, this decrease in iNOS mRNA correlated with a significant decrease in nitrite levels. Previous studies have shown that decreased production of $\mathrm{NO}$ and prostanoids is associated with improved circular muscle function. ${ }^{17212245}$ Thus CO inhalation selectively decreased the intensity of the proinflammatory milieu within the graft intestinal muscularis by blunting the post-transplant levels of IL-6, IL-1 $\beta$, iNOS, and COX-2. However, no significant change was observed in the transplant induced upregulation of TNF- $\alpha$.

Two anti-inflammatory pathways that have been shown to be important in the gut are IL- 10 and HO- $1 .{ }^{46-48}$ As HO- 1 and CO have previously been linked to IL- $10,{ }^{11}{ }^{49}$ we investigated in the above experiments the effects of $\mathrm{CO}$ on IL-10 and HO- 1 expression. The data above demonstrated that both IL-10 and HO- 1 are activated as potential anti- inflammatory mechanisms following transplantation. Coinduction of these two pathways appears to be important because HO-1 mediates the inhibitory effects of IL-10 on lipopolysaccharide induced TNF- $\alpha .^{49}$ In addition to $\mathrm{CO}$, antioxidant HO- 1 products bilirubin and ferritin may also contribute to decreasing the detrimental effects of the transplant induced antiinflammatory milieu. ${ }^{\text {" }}$

This study shows that $\mathrm{CO}$ attenuates the post-transplant inflammatory milieu by selectively decreasing induction of IL-6 and IL-1 $\beta$. Functionally, CO was shown to improve posttransplant motility by limiting the autocrine effects of iNOS and COX-2 produced nitric oxide and prostanoids and by 
restraining the immune and potential enteric neuronal effects of IL- 6 and IL-1 $\beta$. The results of these experiments suggest that clinically providing $\mathrm{CO}, \mathrm{a}$ product of the antiinflammatory HO-1 pathway, may prove to be an effective therapeutic adjunct to overcome the Sisyphean challenges of clinical small bowel transplantation.

\section{ACKNOWLEDGEMENTS}

This work was supported by GM-5824l and GM-53789 to AJB, DK54232 to NM, HL60234, AI42365, and HL55330 to MKC, and American Heart 160332U and Atorvastatin Pfizer Research Award to LEO.

\section{Authors' affiliations}

A Nakao, N Murase, B S Zuckerbraun, Thomas E Starz

Transplantation Institute, University of Pittsburgh, Pittsburgh, PA 15261, USA

B A Moore, A J Baver*, Department of Medicine/Gastroenterology University of Pittsburgh, Pittsburgh, PA 15261, USA

F Liu, A M K Choi, L E Otterbein*, Department of Pulmonary, Allergy, and Critical Care Medicine, University of Pittsburgh, Pittsburgh, PA 15261, USA

F H Bach, Beth Israel Deaconess Medical Center, Harvard Medical School, Boston, MA, USA

M A Nalesnik, Department of Pathology, University of Pittsburgh, Pittsburgh, PA 15261, USA

${ }^{*} \mathrm{~A} J$ Bauer and L E Otterbein contributed equally to this work.

\section{REFERENCES}

1 Tsiotos GG, Kendrick ML, Libsch K, et al. lleal absorptive adaptation to jejunal resection and extrinsic denervation: implications for living-related small bowel transplantation. J Gastrointest Surg 2001:5:517-24.

2 Tanaka T, VanKlompenberg LH, Sarr MG. Selective role of vagal and nonvagal innervation in initiation and coordination of gastric and small bowel patterns of interdigestive and postprandial motility. J Gastrointest Surg 2001;5:418-33

3 Tanaka T, Kendrick ML, Zyromski NJ, et al. Vagal innervation modulates motor pattern but not initiation of canine gastric migrating motor complex. Am J Physiol Gastrointest Liver Physiol 2001·281:G283-92.

4 Kendrick ML, Meile T, Zyromski NJ, et al. Extrinsic neural innervation mediates absorption of water and electrolytes in canine proximal colon in vivo. J Surg Res 2001;97:76-80.

5 Baver AJ. Transplantation-induced injuries to the intestinal muscularis and its innervation: from preservation to chronic rejection. Transplant Proc 1996:28:2539-41

6 Schwarz NT, Nakao A, Nalesnik MA, et al. Protective effects of ex vivo graft radiation and tacrolimus on syngeneic transplanted rat small bowel motility. Surgery 2002;131:413-23.

7 Nishida S, Levi D, Kato T, et al. Ninety-five cases of intestinal transplantation at the University of Miami. J Gastrointest Surg 2002;6:233-9.

8 Abu-Elmagd K, Reyes J, Bond G, et al. Clinical intestinal transplantation: a decade of experience at a single center. Ann Surg $2001 ; 234: 404-16$

9 Abu-Elmagd K, Todo S, Tzakis A, et al. Intestinal transplantation and bacterial overgrowth in humans. Transplant Proc 1994;26:1684-5.

10 Garrido V, Bond GJ, Mazariegos G, et al. Late severe rejection of intestinal allografts: risks and survival outcome. Transplant Proc 2001:33:1556-7.

11 Otterbein LE, Choi AM. Heme oxygenase: colors of defense against cellular stress. Am J Physiol Lung Cell Mol Physiol 2000;279:L1029-37

12 Sato K, Balla J, Otterbein LE, et al. Carbon monoxide generated by heme oxygenase- 1 suppresses the rejection of mouse-to-rat cardiac transplants. J Immunol 2001;166:4185-94.

13 Brouard S, Otterbein LE, Anrather J, et al. Carbon monoxide generated by heme oxygenase 1 suppresses endothelial cell apoptosis. J Exp Med 2000; 192:1015-26.

14 Fujita T, Toda K, Karimova A, et al. Paradoxical rescue from ischemic lung injury by inhaled carbon monoxide driven by derepression of fibrinolysis. Nat Med 2001;7:598-604.

15 Murase N, Demetris AJ, Kim DG, et al. Rejection of multivisceral allografts in rats: a sequential analysis with comparison to isolated orthotopic small-bowel and liver grafts. Surgery 1990;108:880-9.

16 Miller MS, Galligan JJ, Burks TF. Accurate measurement of intestinal transit in the rat. J Pharmacol Methods 1981;6:211-17

17 Eskandari MK, Kalff JC, Billiar TR, et al. LPS-induced muscularis macrophage nitric oxide suppresses rat jejunal circular muscle activity. Am J Physiol Gastrointest Liver Physiol 1999;277:G478-86.

18 Sheibani K, Lucas FV, Tubbs RR, et al. Alternate chromogens as substitutes for benzidine for myeloperoxidase cytochemistry. Am J Clin Pathol 1981;75:367-70.

19 Turler A, Kalff JC, Heeckt $P$, et al. Molecular and functional observations on the donor intestinal muscularis during human small bowel transplantation. Gastroenterology 2002;1 22:1886-97.
20 Schmittgen TD, Zakrajsek BA, Mills AG, et al. Quantitative reverse transcription- polymerase chain reaction to study mRNA decay: comparison of endpoint and real-time methods. Anal Biochem 2000;285: 194-204.

21 Schwarz NT, Kalff JC, Turler A, et al. Prostanoid production via COX-2 as a causative mechanism of rodent postoperative ileus. Gastroenterology 2001;121:1354-71.

22 Kalff JC, Schraut WH, Billiar TR, et al. Role of inducible nitric oxide synthase in postoperative intestinal smooth muscle dysfunction in rodents. Gastroenterology 1999;188:316-27.

23 Cicalese L, Heeckt PF, Baver AJ. Transplantation-induced ischemia reperfusion injury results in a massive infiltration of leukocytes into the muscularis and a subsequent decrease in muscle function. Gastroenterology 1997;110:A319.

24 Cicalese L, Halfter W, Heeckt PF, et al. Leukocyte infiltration of the graft muscularis and its effect on muscle function during acute rejection of rat intestinal allografts. Transplant Proc 1996;28:2459.

25 Cicalese L, Halfter WM, Heeckt PF, et al. Immunocyte infiltration of the graft muscularis and its effect on muscle function during acute rejection of rat small intestinal allografts. Transplant Proc 1996;28:2459.

26 Heeckt PF, Halfter WM, Schraut WH, et al. Small bowel transplantation and chronic rejection alter rat intestinal smooth muscle structure and function. Surgery 1993;114:449-56.

27 Heeckt PF, Lee KKW, Halfter WM, et al. Functional impairment of enteric smooth muscle and nerves caused by chronic intestinal allograft rejection regresses after FK506 rescue. Transplantation 1995:59:159-64

28 Heeckt PF, Halfter W, Schraut WH, et al. Chronic rejection causes early destruction of the intrinsic nervous system in rat intestinal transplants. Am J Physiol Gastrointest Liver Physiol 1997;36:G413-21.

29 Fujita T, Toda K, Karimova A, et al. Paradoxical rescue from ischemic lung injury by inhaled carbon monoxide driven by derepression of fibrinolysis. Nat Med 2001;7:598-604.

30 Coito AJ. Heme oxygenase-1 gene transfer inhibits inducible nitric oxide synthase expression and protects genetically fat Zucker rat livers from ischemia-reperfusion injury. Transplantation 2002;74:96-102.

31 Soares MP, Lin Y, Anrather J, et al. Expression of heme oxygenasecan determine cardiac xenograft survival. Nat Med 1998;4:1073-7.

32 Guo X, Shin VY, Cho CH. Modulation of heme oxygenase in tissue injury and its implication in protection against gastrointestinal diseases. Life Sci 2001:69:3113-19.

33 Clark JE, Foresti R, Green CJ, et al. Dynamics of haem oxygenase- 1 expression and bilirubin production in cellular protection agains oxidative stress. Biochem J 2000;348:615-19.

34 Hangaishi $\mathbf{M}$, Ishizaka N, Aizawa T, et al. Induction of heme oxygenase-1 can act protectively against cardiac ischemia/reperfusion in vivo. Biochem Biophys Res Comm 2000:279.582-8.

35 Minamino T, Christou H, Hsieh CM, et al. Targeted expression of heme oxygenase- 1 prevents the pulmonary inflammatory and vascular responses to hypoxia. Proc Natl Acad Sci U S A 2001;98:8798-803.

36 Otterbein LE, Bach FH, Alam J, et al. Carbon monoxide has anti-inflammatory effects involving the mitogen-activated protein kinase pathway. Nat Med 2000:6:422-8.

37 Otterbein LE, Mantell LL, Choi AM. Carbon monoxide provides protection against hyperoxic lung injury. Am J Physiol 1999;276:L688-94

38 Wang WP, Guo X, Koo MWL, et al. Protective role of heme oxygenase- 1 on trinitrobenzene sulfonic acid-induced colitis in rats. Am J Physiol Gastrointest Liver Physiol 2001;281:G586-94.

39 Fujita T, Toda K, Karimova A, et al. Paradoxical rescue from ischemic lung injury by inhaled carbon monoxide driven by derepression of fibrinolysis. Nat Med 2001;7:598-604

40 Turler A, Schwarz NT, Turler E, et al. MCP-1 causes leukocyte recruitment and subsequently endotoxemic ileus in rat. AJP Gastrointest Liver Physiol 2001;282:G145-55.

41 Kalff JC, Schraut WH, Billiar TR, et al. Role of inducible nitric oxide synthase in postoperative intestinal smooth muscle dysfunction in rodents. Gastroenterology 2000;1 18:316-27.

42 Collins SM. Interleukin- 1 beta modulation of norepinephrine release from rat myenteric nerves. Am J Physiol 1993;264:G30-5

43 Collins SM, Blennerhassett $\mathrm{P}$, Vermillion DL, et al. Impaired acetylcholine release in the inflamed rat intestine is T cell independent. Am J Physiol 1992:263:G198-201

44 Galeazzi F, Lovato P, Blennerhassett PA, et al. Neural change in Trichinella-infected mice is MHC II independent and involves M-CSF-derived macrophages. Am J Physiol Gastrointest Liver Physiol 2001;281:G151-8.

45 Hori $M$, Kita M Torihashi S, et al. Upregulation of iNOS by COX-2 in muscularis resident macrophage of rat intestine stimulated with LPS. Am J Physiol Gastrointest Liver Physiol 2001;280:G930-8

46 Tons C, Klosterhalfen B, Klein HM, et al. Induction of heat shock protein 70 (HSP70) by zinc bis (DL-hydrogen aspartate) reduces ischemic small-bowel tissue damage in rats. Langenbecks Arch Chir 1997:382:43-8

47 Squiers EC, Bruch D, Buelow R, et al. Pretreatment of small bowel isograft donors with cobalt-protoporphyrin decreases preservation injury Transplant Proc 1999;31:585-6.

48 Xing BG, Hogaboam CM, Gauldie J, et al. Interleukin 10 gene transfer prevents experimental colitis in rats. Gut 2000;46:344-9.

49 Lee TS, Chau LY. Heme oxygenase- 1 mediates the anti-inflammatory effect of interleukin-10 in mice. Nat Med 2002;8:240-6. 